\title{
Reattachment of Fractured Anterior Teeth Fragments - Case Reports
}

\author{
Murali Krishnam Raju S ${ }^{*}$, Sita Rama Kumar $\mathrm{M}^{2}$, Mohan RB ${ }^{3}$, Samuel GS ${ }^{4}$ and Ravi Kumar K ${ }^{5}$
}

${ }^{1}$ Reader, Department of Conservative Dentistry and Endodontics, GSL Dental College, Rajahmundry, Andhra Pradesh, India ${ }^{2}$ Reader, Department of Conservative Dentistry and Endodontics, Vishnu Dental College, Bhimavaram, Andhra Pradesh, India

${ }^{3}$ Reader, Department of Conservative Dentistry and Endodontics, Gitam Dental College, Visakhapatnam, Andhra Pradesh, India

${ }^{4}$ Senior lecturer, Department of Conservative Dentistry and Endodontics, GSL Dental College, Rajahmundry, Andhra Pradesh, India

${ }^{5}$ Senior lecturer, Department of Conservative Dentistry and Endodontics, Gitam Dental College, Visakhapatnam, Andhra Pradesh, India

*Corresponding author: Murali Krishnam Raju S, Reader, Department of Conservative Dentistry and Endodontics, GSL Dental College, Rajahmundry, Andhra Pradesh, India, Tel: 91-9494567272, E-mail: muraliraju.saripella@gmail.com Citation: Murali Krishnam Raju S, Sita Rama Kumar M, Mohan RB, Samuel GS and Ravi Kumar K (2018) Reattachment of Fractured Anterior Teeth Fragments - Case Reports. SAJ Case Rep 5: 105

Article history: Received: 01 February 2018, Accepted: 22 February 2018, Published: 26 February 2018

\begin{abstract}
Background: Anterior crown fractures are common form of traumatic dental injuries that mainly affect the maxillary central incisors. Reattachment of fractured tooth fragments for managing coronal tooth fractures is considered when tooth fragment is available and there is no or minimal violation of the Biological width.

Case Details: We report two cases of coronal tooth fracture that were successfully treated using tooth fragment reattachment.

Conclusion: Reattachment provides good esthetics, restores immediate function and provides positive psychological support to the patient.
\end{abstract}

Keywords: Biologic width; Traumatic dental injuries; Reattachment

\section{Introduction}

Traumatic injuries to teeth and their supporting tissues usually occur in young people and damage may vary from enamel fracture to avulsion [1,2]. Uncomplicated crown fracture (without pulpal involvement) is the most common traumatic dental injury to permanent teeth and the teeth most commonly affected are maxillary incisors. This is attributable to their anterior position and protrusion caused by eruptive pattern [3]. Complicated crown fractures (with pulpal involvement) occur in $0.9 \%$ to $13 \%$ of all dental injuries [4].

Managing coronal tooth fractures, especially when there is no or minimal violation of the biological width, is the reattachment of the dental fragment when it is available. Tooth fragment reattachment offers a conservative, esthetic, and cost effective restorative option that has been shown to be an acceptable alternative to the restoration of the fractured tooth [5-8]. Tooth fragment reattachment allows restoration of the tooth with minimal sacrifice of the remaining tooth structure this technique is less timeconsuming and provides a more predictable long-term wear than when direct composite is used [9]. Clinical trials and long-term follow-up have reported that reattachment using modern dentin bonding agents or adhesive luting systems may achieve functional and esthetic success [10]. These case reports deals with the management of uncomplicated \& complicated crown-root fracture with fragment reattachment procedure

\section{Case Report}

\section{Case report - 1 (Uncomplicated tooth fracture)}

An 11 year old boy came to Conservative dentistry and Endodontics department following traumatic fracture of maxillary central incisors (Figure 1). The fractured portion of 21 was recovered and stored in saline to prevent discoloration from dehydration 
(Figure 2). Clinical \& radiographic examination revealed uncomplicated tooth fracture (Ellis class II) with no evidence of pulpal exposure, mobility or root fracture of 21 \& Ellis class III fracture of 11(Figure 3). The treatment plan of choice was to reattach dental fragment of the 21 and root canal treatment of 11 . The fragment was tried in intraorally to check for proper positioning and fit with the fractured coronal structure.

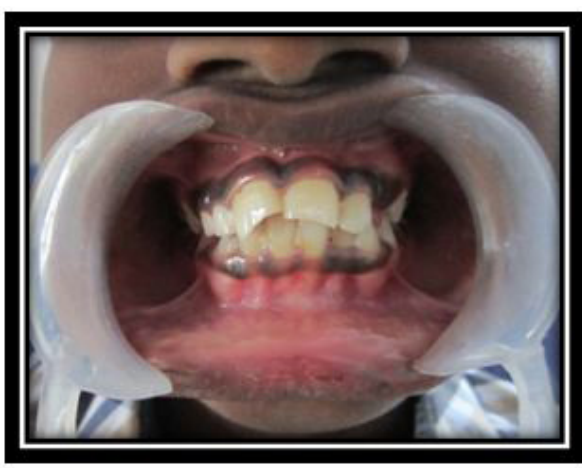

Figure 1: Pre-operative view

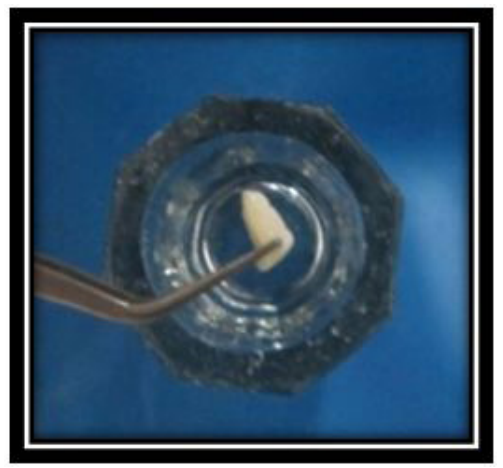

Figure 2: Fractured tooth fragment

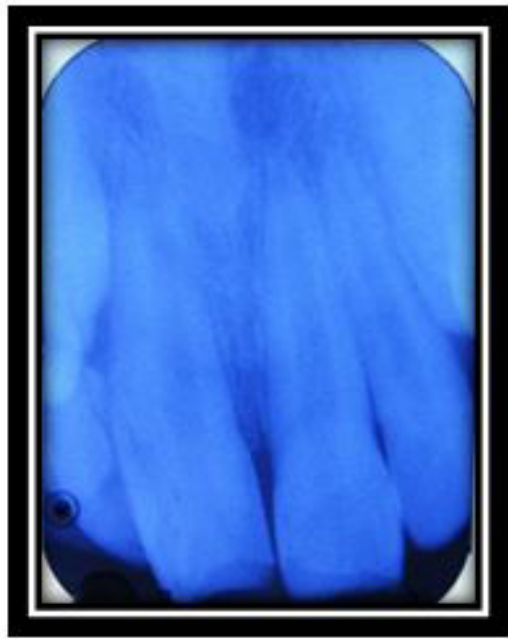

Figure 3: IOPA of $11 \& 21$

The operating field was isolated and the fractured surfaces of the tooth \& fragments were cleaned with treated with $37 \%$ phosphoric acid gel for 30 seconds, followed by rinsing (Figure 4). The adhesive system (Prime and Bond NT, Dentsply) was then applied to the etched surfaces \& light cured (Figure 5). Flowable composite (Ivoclar vivadent) was applied to both fragment and tooth surfaces. When the original position had been reestablished, stable finger pressure was applied on the fragment, excess resin was removed and the area was light-cured. Additional composite was placed after the first cure in order to restore any undercountoured areas. Margins were properly finished with diamond burs and polished with a series of Sof-Lex disks (3M ESPE) and diamond polishing paste. The immediate postoperative view shows adequate esthetic results with restored functionality (Figure 6).

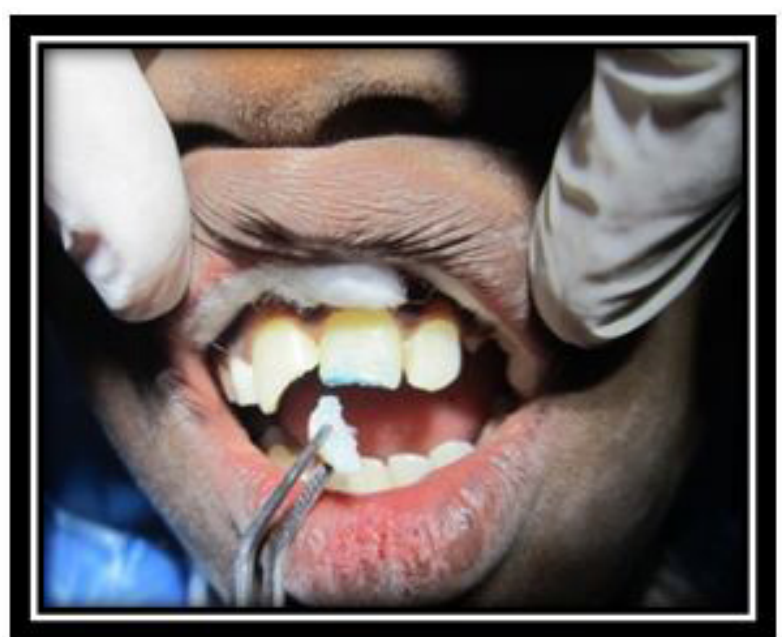

Figure 4: $37 \%$ phosphoric acid gel was applied Onto the tooth \& the fragment

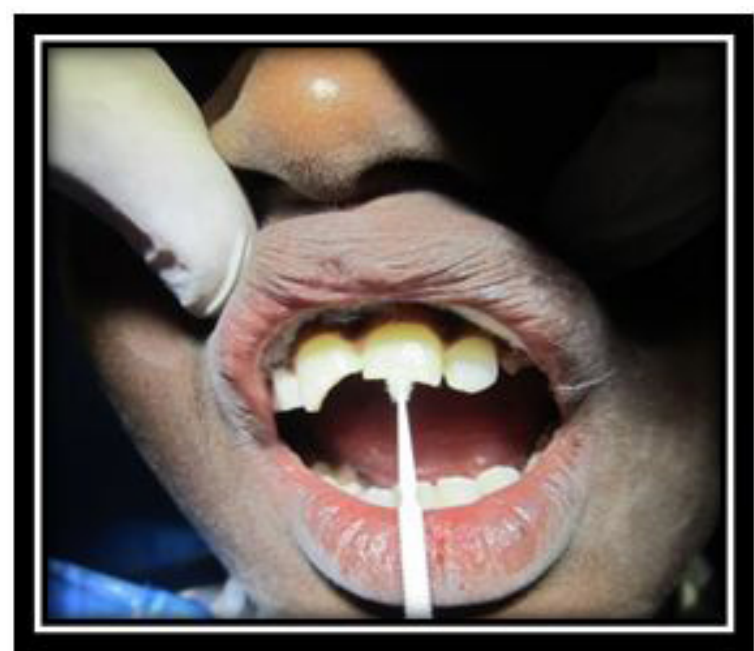

Figure 5: Application of bonding agent 


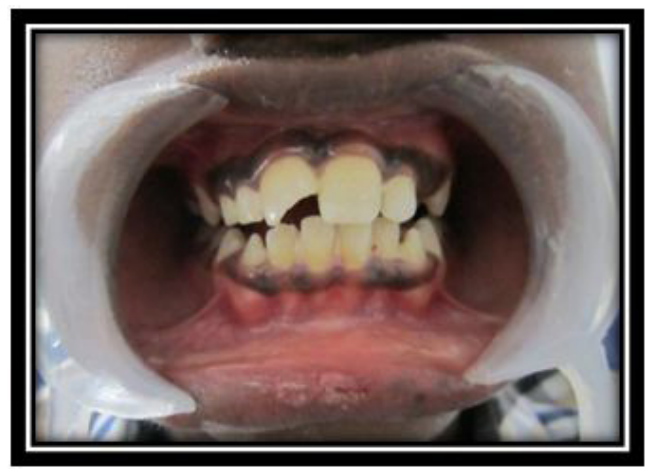

Figure 6: Post-operative view

\section{Case report - 2 (Complicated tooth fracture)}

A 20 year old man came to Conservative dentistry and Endodontics department following traumatic injury. The intra oral examination and radiological examination revealed a complicated crown fracture (Ellis Class III fracture) without any evidence of fracture in root $\&$ the fracture line was oblique running labio-palatally (Figure 7a). The fractured portion was recovered and stored in saline to prevent discoloration from dehydration (Figure 7b). After confirming that the fragment was in good condition and that it fit reasonably well on the fractured tooth, the advantages \& disadvantages, prognosis of the reattachment procedure explained to the patient and he opted to have the tooth fragment reattached.
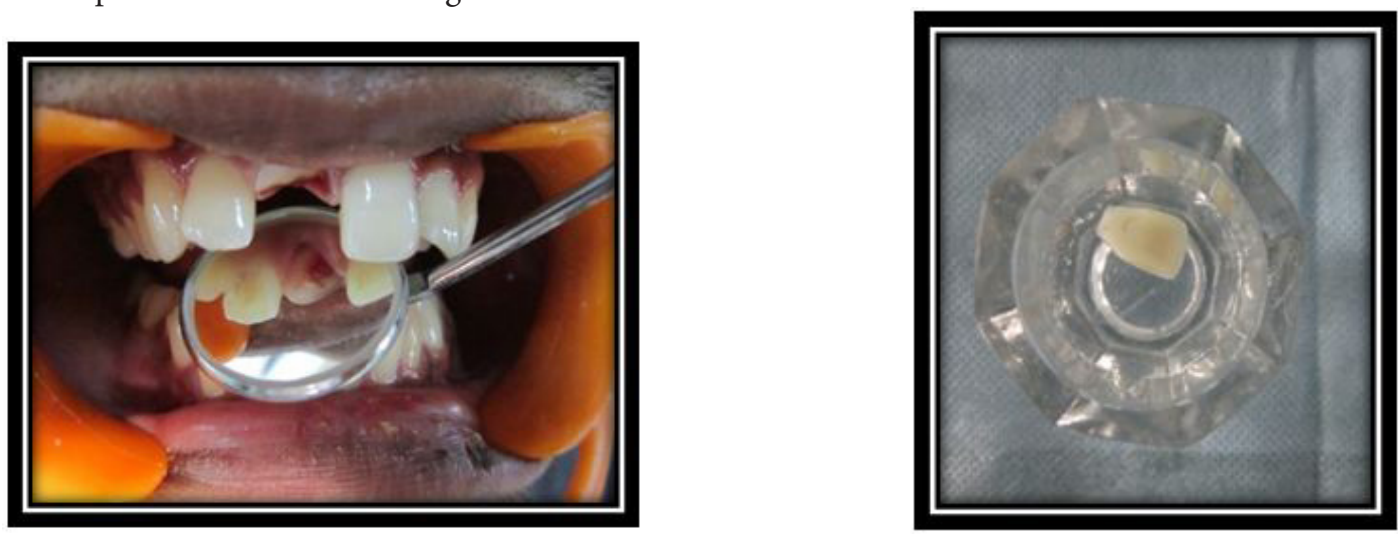

Figure 7: a)Pre-operative view; b) Fractured tooth fragment

After isolating the area, access was gained labially through the fractured region. The pulp tissue was extirpated and the root canal was irrigated with $5.25 \%$ sodium hypochlorite $(\mathrm{NaOCl})$ and saline. Root canal was negotiated with a no.15 $\mathrm{k}$-file, the working length was determined using an electronic apex locator (Root ZX II, Dentsply, Maillefer, Ballaigues, Switzerland). The root canal was cleaned with $5.25 \% \mathrm{NaOCl}$ and $17 \%$ ethylene diamine tetraacetic acid and shaped with protaper files (up to size F3).Obturation was done with protaper Gutta-percha (F3 size) and AH plus sealer. The root canal was obturated with a temporary restoration (Cavit G, 3M-ESPE, Germany).

The day after completion of the endodontic treatment, Post space preparation was done with the corresponding drill to receive a prefabricated glass fiber post [Reforpost, Angelus]. The prefabricated post was checked in the canal for adaptation. Self-adhesive dual cure resin cement (Multilink speed; Ivoclar Vivadent AG, Schaan, Liechtenstein) was used for luting fiber post \& reattaching coronal fragment. Resin cement was delivered from the automix tip into the post space $\&$ on the fiber post. The post was then seated into the canal and the excess cement was removed. Polymerization was done for 40 seconds through the post (Figure 8).

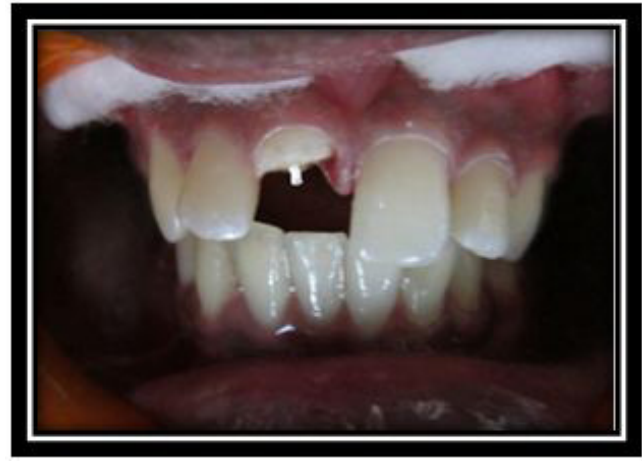

Figure 8: Cemented fiber post 
The fragment was then adapted to the tooth and fit was verified. Resin cement (Multilink speed ; ivoclar Vivadent AG, Schaan, Liechtenstein) was applied to the fractured fragment, the post and the fractured tooth and the fragment was carefully repositioned. Excess cement was carefully removed from the margins and final curing was done for 40 seconds. Margins were properly finished. The immediate postoperative view shows adequate esthetic results with restored functionality (Figures 9 and 10).

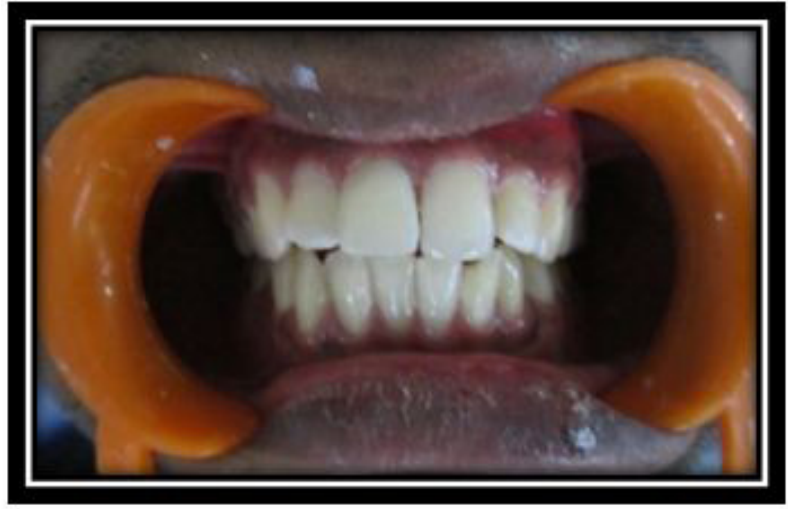

Figure 9: Post-operative view

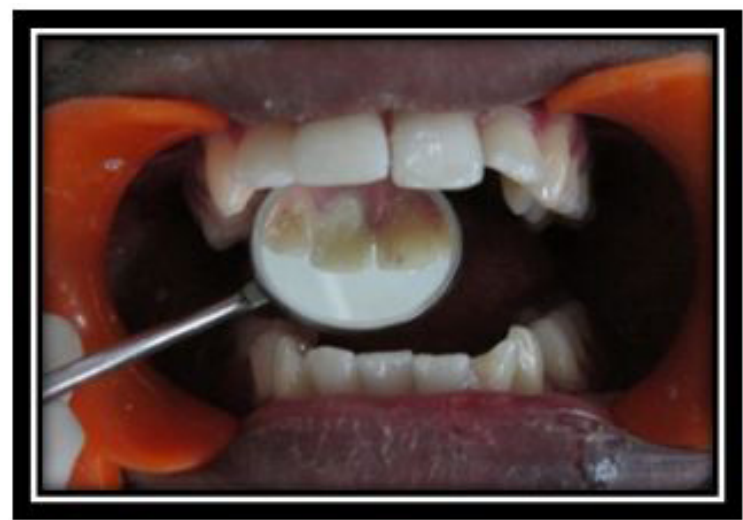

Figure 10: Post-operative palatal view

\section{Discussion}

Management of crown and crown-root fractures pose a challenge to the clinician as several factors may play a role in their management. These factors include [11]

- The extent of the fracture (complicated or uncomplicated, violation of biological width, alveolar bone fracture, concomitant luxation injury)

- Restorability of the fractured tooth and fracture pattern (subgingival extension of the fracture line and/ or associated root fracture)

- Availability of the fractured fragment and its condition for use (fit of the fragment to the remaining tooth structure)

- Secondary soft-tissue injuries

- Occlusion, esthetics and finance

Whenever possible, reattachment of the fractured fragment is one of the best techniques for the restoration of a fractured anterior tooth. It is esthetically more predictable for translucency, opalescence, has favorable wear mechanism, maintains the original tooth contours, preserve identical occlusal contacts, cost effective and a convenient treatment as comparison to other treatments [12,13]. There are various treatment modalities like composite restoration, orthodontic extrusion, surgical extrusion, crown lengthening and reattachment of fractured fragment, followed by Post and Core supported restorations [14-16].

In Case 1, as the fracture is uncomplicated simple reattachment of the fragment was done. total etch technique was used for reattachment due to its ability to minimize the potential for microleakage and enhance bond strength to enamel and dentin [17,18].

In Case 2, fiber post is used as an auxiliary retention owing to the complexity of fracture. Fiber post was preferred over a metallic post because they have better esthetics; their modulus of elasticity is similar to that of root dentine. This results in less stress concentration on the root and thus low incidence of root fracture [19].

Several factors contribute to render post luting procedures difficult: the lack of direct vision and the limited access to the bonding substrate make cementation procedures very technique-related. Moisture control within root canals represents an additional limitation during the management of multi-step resin cements [20]. So self-adhesive resin cement was used for luting and reattaching the fragment because of simplified luting Procedure and has been designed to be less technique-sensitive than their multistep counterparts.

Although rebonding technique offers several advantages there are few disadvantages such as color change of the fragment, exposure and discoloration of the fracture line over a period of time, less strength compared to full coverage restoration and unknown longterm survival rates.

\section{Conclusion}

Reattachment of fractured tooth fragments offers a viable restorative option for the clinician because it restores tooth function and esthetics with the use of a very conservative and cost-effective approach. Also provide immediate natural esthetics and functional rehabilitation.

\section{References}

1. Andreasen JO, Andreasen FM, Andersson L (2007) Textbook and color atlas of traumatic injuries to the teeth. (4 ${ }^{\text {th }}$ edn) Oxford: Blackwell.

2. Simonsen RJ (1982) Restoration of a fractured central incisor using original tooth fragment. J Am Dent Assoc 105: 646-64.

3. Andreasen JO, Ravn JJ (1972) Epidemiology of traumatic dental injuries to primary \& permanent teeth in a Danish population sample. Int J Oral Surg 1: 235-9. 
4. Suroglu I, Sonmez H (2002) The prevalence of traumatic injuries treated in the pedodontic clinic of Ankara university,Turkey,during 18 months. Dent Traumatol 18: 299-303.

5. Andreasen FM, Noren JG, Andreasen JO, Engelhardtsen S, Lindh-Strömberg U (1995) Long term survival of fragment bonding in the treatment of fractured crowns. Quintessence Int 26: 669-81.

6. El-Askary FS, Ghalab OH, Eldemerdash FH, Ahmed OI, Fouad SA, et al. (2006) Reattachment of a severely traumatized maxillary central incisor, one-year clinical evaluation: a case report. J Adhes Dent 8: 343-9.

7. Reis A, Loguercio AD, Kraul A, Matson E (2004) Reattachment of fractured teeth: a review of literature regarding techniques and materials. Oper Dent 29: 22633.

8. Rappelli G, Massaccesi C, Putignano A (2002) Clinical procedures for the immediate reattachment of a tooth fragment. Dent Traumatol 18: 281-4.

9. Maia EA, Baratieri LN, de Andrada MA, Monteiro S, de Araújo EM (2003) Tooth fragment reattachment: fundamentals of the technique and two case reports. Quintessence Int 34: 99-107.

10. Baratieri LN, Monteiro S, Andrada MA (1990) Tooth fracture reattachment: case reports. Quintessence Int 21: 261-70.

11. Macedo GV, Diaz PI, De O Fernandes CA, Ritter AV (2008) Reattachment of anterior teeth fragments: A conservative approach. J Esthet Restor Dent 20: 5-18.

12. Goenka P, Marwah N, Dutta S (2010) Biological approach for management of anterior tooth trauma: Triple case report. J Indian Soc Pedod Prev Dent 28: 223-9.

13. Rajput A, Talwar S, Ataide I, Verma M, Wadhawan N (2011) Complicated Crown-Root Fracture treated Using Reattachment Procedure: A Single Visit Technique. Case rep Dent. 2011: 1-5.

14. Kumar A, Jyothi KN (2010) Reattachment of Fractured Tooth Using Self Etching Adhesive and Esthetic Fiber Post. J Dent Sci Res 1: 75-83.

15. Cohen BI, Musikant BL, Deutsch AS (1996) Clinical Use of the Access Post System. Dental News 3: 23-6.

16. Gaikwad AA. Reiforcing esthetic with fiber post. Int J of Dent Clin 3: 89-90.

17. Kanca J (1992) improving bond strength through etching of dentin and bonding to wet dentin surfaces. J Am Dent Assoc 123: 35-43.

18. Nakabayashi N, Nakamura M, Yasuda N (1991) Hybrid layer as a dentin - bonding mechanism. J esthet Dent 3: $133-8$.

19. Akkayan B, Gülmez T. Resistance to fracture of endodontically treated teeth restored with different post systems (2002) J Prosthet Dent 87: 431-7.

20. Chersoni S, Acquaviva GL, Prati C, Ferrari M, Grandini S, et al. (2005) In vivo fluid movement through dentin adhesives in endodontically treated teeth. J Dent Res 19: 223-7. 